\title{
EDUCAÇÃO FÍSICA ESCOLAR S.A.: MUDANÇAS E SUBJETIVIDADES NA NORMA CORPORATIVA
}

\author{
Renato Cavalcanti Novaes ${ }^{1,2}$ \\ Felipe da Silva Triani ${ }^{3,2}$ (D) \\ Antonio Jorge Gonçalves Soares ${ }^{4}$ \\ Silvio de Cassio Costa Telles ${ }^{2,5}$
}

\begin{abstract}
RESUMO: Neste texto, apresentamos um processo de mudança na Educação Física escolar, no qual forças externas, caracterizadas por grupos políticos e de interesse comercial, sobrepõem-se às internas, compostas por tradições acadêmicas. Demonstramos que, enquanto as tradições acadêmicas desempenharam um protagonismo nas políticas públicas de currículo a partir do final da década de 1990, com a promulgação da Base Nacional Comum Curricular (BNCC) emergiram novos atores sociais e insumos curriculares que oferecem um novo sentido para essa disciplina, marcado, principalmente, por uma racionalidade neoliberal. Ao final, apontamos para o perigo de tal mudança, uma vez que o discurso neoliberal atravessa o espaço-tempo escolar.
\end{abstract}

Palavras-chave: Educação Física. Currículo. Neoliberalismo. BNCC.

\section{SCHOOL PHYSICAL EDUCATION PLC: CHANGES AND SUBJECTIVITIES IN THE CORPORATE RULE}

\begin{abstract}
This text presents a process of change in school Physical Education, in which external qualification, characterized by political and commercial interest groups, overlaps academic traditions. It demonstrates that, while academic traditions had been protagonists in public curriculum policies from the 1990s, with the promulgation of the National Common Curricular Base (BNCC; in Portuguese, base nacional comum corrucilar), new social actors and curricular products emerged and point towards a new sense for this discipline, characterized by a neoliberal rationality. In the end, we point to the danger of these changes, since the neoliberal discourse crosses the school space-time.
\end{abstract}

Keywords: Physical Education. Curriculum. Neoliberalism. BNCC.

Este artigo é fruto da tese de doutorado intitulada "Educação Física Escolar S.A.: desconstruindo o discurso neoliberal", em andamento no Programa de Pós-graduação em Ciências do Exercício e do Esporte da Universidade do Estado do Rio de Janeiro

1.Marinha do Brasil - Centro de Instrução Almirante Alexandrino - Rio de Janeiro (RJ), Brasil. E-mail: rennovaes@hotmail.com

2.Universidade do Estado do Rio de Janeiro - Programa de Pós-graduação em Ciências do Exercício e do Esporte - Rio de Janeiro (RJ), Brasil. 3.Universidade Estácio de Sá - Rio de Janeiro (RJ), Brasil. E-mail:felipetriani@gmail.com

4.Universidade Federal do Rio de Janeiro - Programa de Pós-graduação em Educação - Rio de Janeiro (RJ), Brasil. E-mail: ajgsoares@gmail.com 5.Universidade Federal do Rio de Janeiro - Programa de Pós-graduação em Educação Física - Rio de Janeiro (RJ), Brasil. E-mail: telles.ntg@terra.com.br

Editor de Seção: Sandra Maria Zákia L Sousa 


\title{
EDUCACIÓN FÍSICA ESCOLAR S.A.: CAMBIOS Y SUBJETIVIDADES EN EL ESTÁNDAR CORPORATIVO
}

\begin{abstract}
RESUMEN: En este texto presentamos un proceso de cambio en la educación física escolar en el cual las fuerzas externas, caracterizadas por grupos políticos e intereses comerciales, se superponen a las internas, compuestas de tradiciones académicas. Demostramos que, si bien las tradiciones académicas desempeñaron un papel de liderazgo en las políticas públicas del currículo desde finales de la década de 1990, con la promulgación de la Base Curricular Común Nacional (BNCC; en portugués, base nacional comum curricular), surgieron nuevos actores sociales e insumos curriculares que ofrecen un nuevo significado para esta disciplina, marcado, principalmente, por una racionalidad neoliberal. Al final, señalamos el peligro de tal cambio, ya que el discurso neoliberal cruza el espacio-tiempo escolar.
\end{abstract}

Palabras-clave: Educación Física. Currículo. Neoliberalismo. BNCC.

\section{Introdução}

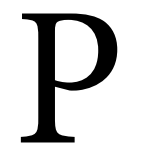

ara Goodson (2013), é fundamental compreender que as disciplinas escolares são artefatos sociais concebidos para realizar objetivos humanos específicos. Esse autor apresenta três hipóteses para entender o processo de constituição das disciplinas escolares (JAEHN; FERREIRA, 2012; GOODSON, 2013). De acordo com a primeira hipótese, as disciplinas são amálgamas mutáveis compostas por tradições que clamam ora por continuidade, ora por mudança. O currículo, portanto, pode ser compreendido como um conjunto de tradições em conflito e em mudança.

Na segunda hipótese, Goodson (2013) defende que as disciplinas escolares possuem diferentes estágios de evolução. Num primeiro momento, ela é introduzida na escola com um caráter utilitário, pressionada pelas demandas do contexto. Em seguida, estabelece-se uma tradição acadêmica, o que inclui a formação de professores especialistas e corpo de conhecimento. No último estágio, a disciplina conta com um conjunto de professores especializados, além de regras e valores bem-instituídos.

Por fim, Goodson (2013) aponta que o currículo é determinado por conflitos em torno do status profissional. O currículo não consiste, portanto, em um artefato despersonalizado, pois é resultante de disputas por diferentes interesses. Os agentes que, em disputa, possuem o poder decisório sobre as disciplinas escolares formam a comunidade escolar: professores e pesquisadores ligados às disciplinas escolares/acadêmicas que tratam de um conhecimento específico (GOODSON, 2013).

Nessa perspectiva, uma disciplina escolar é decorrente do:

[...] trabalho de acadêmicos especialistas e atuando como iniciadores nas tradições acadêmicas, sendo geralmente aceita tanto por educadores como por leigos. É uma visão sustentada por porta-vozes governamentais e agências educacionais, associações de disciplinas e, talvez de forma mais importante, pela mídia (GOODSON, 1990, p. 234).

Novaes (2015), baseado nas hipóteses pregressas de Goodson (2013), demonstrou a transição da Educação Física de caráter utilitário, que objetivava a construção de corpos úteis para o Estado (como força de defesa ou de trabalho), para a tradição curricular acadêmica, desencadeada, 
principalmente, pelo chamado "movimento renovador da Educação Física", o qual emergiu em torno da década de 1980 no Brasil. Boa parte desse processo da transformação nessa disciplina escolar se deu na relação entre as forças internas no campo e as demandas e alterações do contexto histórico.

Contudo, os mais recentes desenvolvimentos sobre a dinâmica dos currículos indicam (GOODSON, 2001, 2014) que os processos de mudança/continuidade nas disciplinas escolares em andamento nas últimas décadas não se limitam aos diálogos entre professores, acadêmicos e as demandas da sociedade organizada. Os grupos de professores e acadêmicos, que outrora foram determinantes para as políticas de currículo, são gradualmente submetidos aos grupos políticos associados a interesses mercantis da educação. Essa hipótese encontra respaldo em estudos no campo da educação no Brasil, como em Macedo (2014) e Adrião et al. (2016), que analisam a participação de diferentes grupos associados a grandes instituições financeiras na elaboração de recentes políticas de currículo, em especial a Base Nacional Comum Curricular (BNCC). Tais pressupostos são corroborados por Ball (2014), quando aponta que:

[...] em diferentes graus, em diferentes países, o setor privado ocupa agora uma gama de funções e de relações dentro do Estado e na educação pública em particular, como patrocinadores e benfeitores, assim como trabalham como contratantes, consultores, conselheiros, pesquisadores, fornecedores de serviços e assim por diante; tanto patrocinando inovações (por ação filantrópica) quanto vendendo soluções e serviços de políticas para o Estado, por vezes de forma relacionada (BALL, 2014, p. 181).

Diante do exposto, este texto tem como objetivo apresentar um processo de mudança na Educação Física escolar (EFE), no qual forças externas se sobrepõem às internas, conforme analisado por Goodson (2014). Na primeira seção, contextualizamos a EFE e suas transformações a partir das forças internas produzidas no desenvolvimento acadêmico da disciplina, seus professores e sua relação com as políticas. Em seguida, apresentamos recentes mudanças na EFE em pleno andamento e deflagradas pela BNCC, quais sejam: a emergência de grupos que se apresentam como filantrópicos e preocupados com a qualidade da educação brasileira; e a relação com o mercado editorial. Assim, pretendemos inserir as práticas e as mudanças na EFE em um contexto cultural mais amplo a partir de uma abordagem histórica e diagnóstica (POPKEWITZ; LINDBLAD, 2016).

\section{Forças Internas de Mudança Educacional}

Os documentos curriculares refletem as narrativas por meio das quais as disciplinas se legitimam (GOODSON; PETRUCCI-ROSA, 2018), o que significa dizer que os fenômenos do currículo e a história de uma disciplina escolar estão intimamente relacionados (GOODSON, 2013). Há, portanto, um movimento duplo na relação entre as políticas públicas de currículo e o conhecimento escolar da disciplina.

$\mathrm{Na}$ perspectiva de análise de Goodson (2013), que remete a um período com menor influência da mercantilização da educação, o autor estabeleceu padrões de mudança nas disciplinas escolares a partir de forças internas. Um dos padrões definidos é apresentado na Tabela 1 e serve para compreendermos algumas dinâmicas e inflexões da EFE a partir das forças internas. 
Tabela 1. Padrão de mudança curricular interna

Estágio

1) A invenção como formulação da mudança

2) A promoção como implementação da mudança

\section{Caracterização}

Invenção surge a partir das ideias/atividades de um grupo de educadores, às vezes como uma resposta a "ondas de opinião", demandas/resistência dos alunos ou invenções do mundo externo. As ideias necessárias para as mudanças estão geralmente disponíveis por um longo período de tempo em diferentes lugares. Apenas algumas dessas invenções efetivamente ocorrerão.

Promoção por grupos de educadores internos ao sistema educacional. As invenções ocorrerão onde e quando as pessoas se interessarem por ideias novas, não apenas pelo seu conteúdo intelectual, mas também como meio de estabelecer uma nova identidade intelectual e um novo papel ocupacional. Dessa forma, grupos com menor status, poucas possibilidades profissionais e até mesmo dificuldades de sobrevivência profissional podem abraçar e promover novas invenções, por exemplo, no caso da disciplina Meio Ambiente. Por outro lado, grupos de maior status podem ignorar oportunidades de mudança por já estarem satisfatoriamente bem-estabelecidos. [...] A promoção das invenções ocorre a partir da percepção da possibilidade de aumento do status profissional.

A promoção de novas invenções, se bem-sucedida, acarreta o estabelecimento de novas categorias ou grupos. Enquanto a promoção é inicialmente gerada internamente, é preciso desenvolver laços externos que sustentem as mudanças. Esse será um estágio importante para assegurar que novas categorias ou sujeitos sejam de fato reconhecidos e "instituicionalizados". A legislação está associada com o desenvolvimento e a manutenção da retórica de legitimidade, que confere apoio automático à atividade profissional.

Assim que o apoio automático foi alcançado por um indivíduo ou pela categoria, uma ampla gama de atividades pode ser realizada. Os limites se estabelecem pelas atividades que ameaçam a retórica da legitimidade estabelecida e, consequentemente, o grupo constituído. O sujeito, nesse momento, possui status mitológico. Ele representa um tipo licença que foi garantida (como uma patente ou um direito autoral) com a plena força da lei que o resguarda. Nesse momento, quando o sujeito foi inventado com sucesso, o processo de invenção e implementação está completo.

Fonte: Goodson (2014, p. 770, tradução nossa).

Devemos observar que esse padrão de mudança destaca como as forças geradas internamente na comunidade escolar caminham no sentido da legitimação externa (GOODSON, 2014). Tais mudanças não são absolutas e podem encontrar resistências, tanto internas quanto externas.

A EFE tem uma longa tradição e sofreu diferentes transformações no processo de escolarização. Como atividade voltada para educação do corpo e de técnicas corporais, sempre esteve presente no projeto da escola moderna e gozava de um caráter eminentemente utilitário e prático, apesar do desenvolvimento acadêmico e profissional do campo. O caráter utilitário e prático da disciplina pode ser observado no DecretoLei n. 69.450, de 1971. A Educação Física na escola tinha por função socializar atividades para formar corpos e mentes "disciplinados e saudáveis". O artigo $1^{\circ}$ do decreto apresentava a seguinte definição:

[...] atividade que, por seus meios, processos e técnicas, desperta, desenvolve, aprimora forças físicas, morais, cívicas, psíquicas e sociais do educando, constituindo um dos fatores básicos para a conquista das finalidades da educação nacional (BRASIL, 1971).

Apesar da longa permanência dessa atividade no currículo escolar, seu caráter utilitário, prático e recreativo lhe conferia um status secundário ou complementar na hierarquia das disciplinas escolares (BRACHT, 1996, 1999; BRANDOLIN; KOLINSKY; SOARES, 2015). Todavia, nos anos 1980, principalmente, 
a partir do processo de abertura política, a Educação Física e o campo da educação em geral colocaram em questão os modelos pedagógicos e a formação política oferecida pela escola. A EFE, nesse período, passou por um importante movimento de ressignificação curricular e os debates e disputas no campo acadêmico da área foram nomeados Movimento Renovador. Nesse contexto, surgiram diversas abordagens pedagógicas/ curriculares apoiadas em referenciais teóricos específicos (marxismo, existencialismo, desenvolvimentismo motor, psicomotricidade, estudos culturais etc.) para propor diferentes projetos identitários para a EFE (NUNES; RUBIO, 2008; BRACHT, 2019). Esse movimento foi impulsionado pelo surgimento de diversos trabalhos decorrentes de programas de pós-graduação nas décadas de 1980 e 1990. Assim, diferentes linhas de pesquisa se debruçaram sobre a EFE nesse período.

Esse processo de renovação da Educação Física, gerado pelas forças internas - pesquisadores e professores - no campo dessa disciplina, seguiu o modelo de Goodson (2013) pelo caminho da legitimação externa. No texto da Lei de Diretrizes e Bases da Educação Nacional (LDBEN), de 1996, podemos constatar essa mudança paradigmática: “a Educação Física, integrada à proposta pedagógica da escola, é componente curricular obrigatório da educação básica [...]” (BRASIL, 1996). Isto é, ela deixa se ser nomeada como atividade para ser considerada um componente curricular.

O movimento de legitimação da EFE, fortemente apoiado no campo acadêmico da Educação Física, ganhou novos contornos em textos curriculares posteriores, nos quais a influência das forças internas pode ser notada de forma mais enfática:

[...] entende-se a Educação Física como uma área de conhecimento da cultura corporal de movimento e a Educação Física escolar como uma disciplina que introduz e integra o aluno na cultura corporal de movimento, formando o cidadão que vai produzi-la, reproduzi-la e transformá-la, instrumentalizando-o para usufruir dos jogos, dos esportes, das danças, das lutas e das ginásticas em benefício do exercício crítico da cidadania e da melhoria da qualidade de vida (BRASIL, 1998, p. 29).

Assim, desde os primeiros Parâmetros Curriculares Nacionais (PCN) para o Ensino Fundamental, passando pelos PCN para o Ensino Médio (2000, 2002), pelas Orientações Curriculares Nacionais (2006) e, mais recentemente, pelos currículos propostos pelas Secretarias Estaduais de Educação, percebe-se nos currículos da EFE a influência das diversas tradições acadêmicas oriundas dos movimentos renovadores (CORREIA, 2014; BRACHT, 2019).

Convém observar que, conforme aponta Macedo (2019), os PCN já indicavam uma entrada das políticas neoliberais nos currículos oficiais brasileiros. Tal orientação curricular se justificava pela exigência de a educação nacional responder às demandas de um mundo globalizado. Os PCN orientavam que o processo de ensino e aprendizagem deve desenvolver competências e habilidades dos estudantes - de certa forma um alinhamento da gramática educacional à do mercado. Nesse período, já havia a expectativa por um currículo centralizado e normativo, mas a oposição da comunidade acadêmica e a falta de força política foram fatores que impediram que os PCN obtivessem efeito de lei (MACEDO, 2014). Nesse sentido, percebe-se maior influência das forças internas de currículo no processo de mudança educacional, embora não se trate de um processo linear e homogêneo.

Devemos observar que essas tradições acadêmicas foram o resultado do trabalho de especialistas que pretenderam repensar a Educação Física. Há, portanto, ainda nesse momento uma relação muito próxima entre as tradições acadêmicas e o trabalho do professor. Embora tal afirmação pareça óbvia, Goodson (2014) aponta que se trata de uma característica desse modelo de mudança nas disciplinas escolares, em oposição ao 
modelo mais recente, no qual as forças externas, os interesses do mercado educacional, ganham mais peso nos processos de transformações das disciplinas e dos currículos.

\section{Forças Externas de Mudança}

Goodson $(2001,2014)$, após uma série de estudos realizados em escolas americanas e canadenses no final da década de 1990, percebe uma alteração nos padrões de mudança contemporâneos, nos quais as forças externas passam a pesar mais que as internas no jogo de forças. Propõe, assim, um novo modelo (Tabela 2) ao considerar que houve uma mudança significativa de forças numa balança entre os agentes internos e externos.

Tabela 2. Padrão de mudança curricular externa

\section{Estágio}

\begin{tabular}{l} 
Estágio \\
\hline \multicolumn{1}{c}{ Declaração dos objetivos } \\
desejados;
\end{tabular}

2) Tradução de objetivos econômicos em contexto educacional;

3) Delineamento de "regras de operação" na educação;

Definida por grupos internos localizados em think-tanks e grupos corporativos. Enfatiza competitividade econômica e questões relacionadas à reestruturação econômica e neoliberal. A educação em si possui pouco valor a não ser no que diz respeito ao mercado de trabalho e à economia.

Instrumentalização de sistemas de valor de mercado no espaço educacional. Educação e currículo se transformam num bem comum como qualquer outro.

Comercialização de procedimentos e práticas escolares, estratificação por meio da diferenciação. Foco em exames para comparação e organização em tabelas de resultados. Professores vistos como técnicos que implementam esse sistema e são pagos pelos resultados obtidos.

A legislação expressa os objetivos econômicos com mecanismos de aplicação direta na educação. O "pânico moral" é encorajado pela mídia, instrumento corporativo, sobre a educação pública - progressiva comercialização dos setores educativos. Entrada corporativa nas escolas e comercialização do currículo (p. ex., definição de um núcleo comum na maior parte dos estados dos EUA e a provisão de livros didáticos publicados por gigantes agências corporativas).

Fonte: Goodson (2014, p. 775-776, tradução nossa).

Esse modelo reformulado de mudança curricular é nomeado por Goodson (2014) "norma corporativa" (corporate rule) e consiste na transferência do peso das forças internas para as forças externas nas mudanças no campo educacional amplo e nas disciplinas escolares. As forças externas aqui se referem à lógica do mercado, que transferem os valores econômicos, como eficiência e competitividade, à educação. Assim, a "norma corporativa" se alinha ao modelo econômico neoliberal:

O período desde 2000 tem sido um período de mudanças tumultuadas e instabilidade nos sistemas financeiros e econômicos. [...] Apesar da crise financeira iniciada em 2007, as grandes corporações consolidaram sua influência na infraestrutura social. [...] Mudamos de uma economia de mercado para uma sociedade de mercado - tudo deve ser vendável e concebido para fins lucrativos. [...] Então, observamos uma "inversão da democracia”: um sistema que já foi criado para representar o povo contra o poder concedido agora parece funcionar para representar esse poder (especialmente o corporativo) contra as pessoas. [...] O neoliberalismo tornou-se uma "teoria de tudo", fornecendo uma versão abrangente sobre o sujeito e sua identidade, o conhecimento e a informação, a economia e o governo (GOODSON, 2014, p. 774, tradução nossa). 
Goodson (2014) argumenta que os agentes internos de mudança enfrentam uma crise de posicionalidade, na qual os agentes internos, ou seja, a comunidade escolar, o que inclui os especialistas acadêmicos (GOODSON, 2013), deixam de iniciar os processos de mudança e passam a se posicionar de forma conservadora, reativa.

Onde a mudança era a missão interna dos educadores e as relações externas aconteciam depois, pressupunha-se a vocação e a paixão educativa. Atualmente, os grupos de educadores assumem menos o papel de agentes ou parceiros das mudanças e são vistos como aplicadores dos objetivos propostos externamente. Educadores deixaram de ser proativos e construtivos para ser reativos e complacentes (GOODSON, 2014, p. 771, tradução nossa).

A culminância desse novo modelo de mudança curricular é a "obrigação e a manipulação" (GOODSON, 2001, 2014). Nessa etapa, a "norma corporativa" aplicada à educação encontra legitimidade na legislação. Goodson (2014) oferece como exemplo a definição de um núcleo comum nos Estados Unidos e a subsequente "necessidade" de livros didáticos que beneficia um gigantesco mercado editorial.

Impossível não associar tal culminância nesse novo modelo de mudança com a promulgação no Brasil da BNCC do Ensino Fundamental, em dezembro de 2017. A defesa de uma base nacional comum não é recente no Brasil, pois o documento da LDBEN, de 1996, já indicava uma

[...] base nacional comum, a ser complementada, em cada sistema de ensino e em cada estabelecimento escolar, por uma parte diversificada, exigida pelas características regionais e locais da sociedade, da cultura, da economia e dos educandos (BRASIL, 1996).

Vale assinalar que esse processo de padronização de uma base curricular e de norma mercadológica da educação remete a um movimento global de crítica extensamente documentado, na literatura tanto internacional (McCARTY, 2009; REID, 2009; RAVITCH, 2011; LOVELESS, 2016) quanto nacional (MOREIRA, 2010; MACEDO, 2014; ADRIÃO et al., 2016; ADRIÃO, 2017; AGUIAR; DOURADO, 2018). Ignorando os estudos que demonstram que as políticas de currículo comum, instituídas em países desenvolvidos e em implantação em países em desenvolvimento, não produziram melhoria da qualidade de ensino (RAVITCH, 2011), o Brasil optou pela elaboração da BNCC.

A BNCC foi amplamente divulgada pela mídia brasileira ${ }^{2}$ como documento de caráter democrático, que funcionaria como garantia dos direitos de aprendizagem a todos os estudantes em território nacional.

O Brasil terá, pela primeira vez, uma Base Nacional Comum Curricular. O documento é democrático, e respeita as diferenças. Com a Base, todos os estudantes do país, de escola pública ou particular, terão os mesmos direitos de aprendizagem. Isso é bom. Se a base da educação é a mesma, as oportunidades também serão (BRASIL, 2018).

Temos que reconhecer que o argumento encontra ressonância na sociedade e se alinha ao imaginário de unidade nacional. Todavia, a noção de democratização da escola contida no texto supracitado é falaciosa, uma vez que os direitos de aprendizagem e as oportunidades não são as mesmas se consideramos que as escolas e as realidades sociais são dramaticamente desiguais no Brasil. Afinal, o tema das desigualdades de oportunidades educacionais é mais complexo e deve ser analisado a partir de variáveis que impactam o sucesso e o insucesso escolar para além de uma base curricular (BOUDON, 1974; MACEDO, 2018). 
No entanto, a implantação da BNCC contou com a participação de novos e poderosos atores sociais. Por meio de parcerias entre os setores público e privado, novos "parceiros" emergiram na última década no Brasil: "Itaú [Unibanco], Bradesco, Santander, Gerdau, Natura, Volkswagen, entre outras - além de Fundação Victor Civita, Fundação Roberto Marinho, Fundação Lemann, CENPEC, Todos pela Educação, Amigos da Escola" (MACEDO, 2014, p. 1540). O protagonismo do setor privado no processo de elaboração da BNCC ocorreu por meio de

[...] financiamento e coordenação de reuniões em que as versões dos documentos foram debatidas e produzidas; formação de pesquisadores em centros internacionais pró-centralização curricular, como Standford; realização de pesquisas que sustentaram a necessidade de currículos nacionais; financiamento de seminários que narraram exitosas experiências internacionais; produção de materiais para a implementação dos currículos; contratação de grupos internacionais para avaliar a experiência em curso, entre muitas outras (MACEDO, 2019, p. 1122).

Ball denomina esse processo de desestatização, no qual os novos atores "estão investidos no edubusiness e no desenvolvimento de soluções sócio empresariais e de mercado para os problemas educacionais" (2014, p. 88). Essa modalidade de negócio não se faz "retirando os serviços do controle do setor público, mas sim por meio da venda de soluções políticas e vias de colaboração de vários tipos com o setor público, embora algumas sejam mais significativamente colaborativas do que outras" (BALL, 2014, p. 162). Essas vias de colaboração são compostas por diferentes "parceiros", que formam redes de atuação constituídas por:

[...] instituições filantrópicas, grandes corporações financeiras que deslocam impostos para suas fundações, produtores de materiais educacionais vinculados ou não às empresas internacionais do setor, organizações não governamentais (MACEDO, 2014, p. 1540).

Há nesse movimento uma desvinculação do sentido tradicional de filantropia. Ball (2014) distingue três momentos dessa alteração de sentido: a filantropia tradicional, paliativa (ou filantropia 1.0); a filantropia para o desenvolvimento (ou filantropia 2.0); e, finalmente, a do tipo doação rentável, a filantropia 3.0. Trata-se, para Ball, de uma nova faceta do capitalismo: o filantrocapitalismo.

Um dos braços dessa nova rede que desemboca na EFE é o Time Impulsiona. O Impulsiona é parte do Instituto Península' uma dessas instituições "filantrópicas" que atuam na educação, e pertence à família de Abílio Diniz. ${ }^{3}$ Segundo o site do Impulsiona, seu programa oferece materiais didáticos, cursos on-line e eventos que visam fomentar o esporte nas escolas, principalmente na rede pública, tendo capacitado, desde 2017, 90 mil professores e chegado a mais de 38 mil escolas em todos os estados do Brasil. ${ }^{4}$

A proposta de capacitação do Impulsiona é oferecer subsídios práticos ao professor de EFE. Alguns dos cursos oferecidos no site do Impulsiona são: Movimento Paralímpico: Fundamentos Básicos do Esporte; Metodologias Ativas da Educação Física; Atletismo na Escola; Orientador de Alunos Líderes; Tênis; Ginástica Artística e, é claro, sobre a implementação da BNCC na Educação Física. Além dos cursos eminentemente práticos sobre os esportes, figuram cursos sobre metodologias ativas de ensino, formação de alunos líderes, entre outros. Para Taubman (2009), uma característica do discurso neoliberal presente nas novas reformas curriculares é justamente a presença das ciências da psicologia que concebem o ensino como um conjunto de práticas objetivas ou técnicas capazes de garantir o aprendizado. 
O que se encontra ausente na lista de cursos do Impulsiona são os debates que permearam o campo teórico da EFE e propunham discutir os pressupostos teóricos que fundamentam as práticas pedagógicas. De certa forma, tais cursos voltam a tratar a EFE como atividade, destituindo de alguma forma seu reconhecimento como disciplina. Taubman (2009) percebe essa mudança no que diz respeito às mudanças nos currículos norte-americanos, fomentadas pelo discurso neoliberal.

As narrativas heurísticas que antes pareciam úteis, como aquelas sobre políticas de identidade, feministas ou neomarxistas, parecem ter "derretido no ar" ou se transformado em polêmicas anacrônicas cantadas em coro, deixando-nos desencorajados e atordoados (TAUBMAN, 2009, p. 15).

Encontramos, assim, um alinhamento do Impulsiona com as redes de atuação da norma corporativa, na qual os debates críticos e pós-críticos sobre o currículo são silenciados quase que por completo. Todavia, se os seus cursos são gratuitos, o que ganham as instituições "filantrópicas" como o Time Impulsiona, o Instituto Península e tantas outras?

Para Ball (2014), deve-se considerar que as ações desses atores privados garantem participação no debate das políticas educacionais e, consequentemente, favorecimento em sua vasta rede de negócios. É preciso dizer que o edubusiness consiste em um negócio bilionário e gera altas taxas de lucro se comparado a tantos outros (MARINGONI, 2017). Em 2018, por exemplo, o grupo Kroton Educacional comprou o grupo Somos Educação pelo valor de 4,6 bilhões de reais. Com isso, a Kroton se anunciou como o maior grupo privado de educação básica do país. Anteriormente, o grupo havia tentado a fusão com o grupo Estácio, mas teve o negócio vetado pelo Conselho Administrativo de Defesa Econômica. ${ }^{5}$

Esses grandes grupos corporativos são compostos por editoras que estão investidas no edubusiness por meio do mercado de "insumos curriculares", compostos por:

[...] livros didáticos, apostilas ou tecnologias de informação em geral; [...] sistemas de gestão envolvendo sistemáticas de avaliação de desempenho de estudantes e de escolas; [...] programas de qualificação de professores; [...] assessorias para a gestão etc. (ADRIÃO; DOMICIANO, 2018, p. 3).

Para Goodson (2014), parte do negócio da implantação de núcleos comuns, como a BNCC, no nosso caso, refere-se ao mercado editorial, principalmente na atuação junto ao ensino público, na medida em que esse é o maior mercado. O projeto da BNCC, por sua vez, está intimamente relacionado a outra política pública: o Programa Nacional do Livro e do Material Didático (PNLD). Esse programa atende escolas públicas da educação básica e tem como objetivo avaliar e disponibilizar material didático e paradidático em todo o território nacional, contemplando cerca de 30 milhões de estudantes brasileiros por ano (GOODSON; PETRUCCI-ROSA, 2018). Desde julho de 2017, por meio do Decreto n. 9.099, o plano objetiva também apoiar a implementação da BNCC (BRASIL, 2017).

Com a divulgação da BNCC, constatamos a publicação de novos materiais didáticos que aderiram ao PNLD no ano de 2019 para apoiar a implantação curricular da Educação Física (Tabela 3). Segundo Oliveira e Petrucci-Rosa, o PNLD exerce grande influência sobre as práticas pedagógicas e as políticas curriculares, pois "além das influências do mercado editorial, de grupos privados e de escolas, destaca-se nessa política a forte participação das comunidades acadêmicas disciplinares” (2016, p. 274). 
Tabela 3. Manuais para o professor de Educação Física adquiridos por meio do PNLD 2019

\begin{tabular}{|c|c|c|c|c|c|c|}
\hline Livro & Volume & Autor(es) & Editora & Ano & $\begin{array}{c}\text { Exemplares } \\
\text { vendidos }\end{array}$ & $\begin{array}{l}\text { Valor total } \\
\quad(\mathrm{R} \$)\end{array}$ \\
\hline \multirow{2}{*}{$\begin{array}{l}\text { Práticas Corporais: } \\
\text { Educação Física - } \\
\text { Manual do Professor }\end{array}$} & $1^{\circ}$ e $2^{\circ}$ anos & \multirow{2}{*}{ Darido et al. } & \multirow{2}{*}{ Moderna } & \multirow{2}{*}{$2017 b$} & 54.282 & $584.863,35$ \\
\hline & $3^{\circ}$ ao $5^{\circ}$ ano & & & & 84.153 & $925.242,90$ \\
\hline \multirow{2}{*}{$\begin{array}{l}\text { Encontros Educação } \\
\text { Física }\end{array}$} & $1^{\circ}$ e $2^{\circ}$ anos & \multirow{2}{*}{$\begin{array}{l}\text { Leopoldino } \\
\text { et al. }\end{array}$} & \multirow{2}{*}{ FTD } & \multirow{2}{*}{$\begin{array}{l}2018 a \\
2018 b\end{array}$} & 40.858 & $210.418,70$ \\
\hline & $3^{\circ}$ ao $5^{\circ}$ ano & & & & 62.470 & $447.285,20$ \\
\hline \multirow{2}{*}{$\begin{array}{l}\text { Manual do } \\
\text { Professor para a } \\
\text { Educação Física }\end{array}$} & $1^{\circ}$ e $2^{\circ}$ anos & \multirow{2}{*}{ Stallivieri } & \multirow{2}{*}{ Terra Sul } & 2017 & 18.318 & $156.985,26$ \\
\hline & $3^{\circ}$ ao $5^{\circ}$ ano & & & 2018 & 29.158 & $316.072,72$ \\
\hline \multirow{2}{*}{$\begin{array}{l}\text { Práticas Corporais } \\
\text { e a Educação Física } \\
\text { Escolar }\end{array}$} & $1^{\circ}$ e $2^{\circ}$ anos & \multirow{2}{*}{ Boog; Urizzi } & \multirow{2}{*}{ Boreal } & \multirow{2}{*}{$\begin{array}{l}2018 a \\
2018 b\end{array}$} & 19.832 & $128.908,00$ \\
\hline & $3^{\circ}$ ao $5^{\circ}$ ano & & & & 31.345 & $162.680,55$ \\
\hline
\end{tabular}

Fonte: Elaboração própria. ${ }^{6}$

Diante da tabela anterior, assinalamos a abertura de um mercado outrora inexistente na EFE. O livro que se destaca nessa lista, pela maior quantidade de exemplares adquiridos pelo PNLD, é Práticas Corporais: Educação Física-Manual do Professor (Fig. 1), que contou com a participação de uma conhecida autora no campo da EFE, a professora Suraya Darido. O manual está dividido em três volumes: um do $1^{\circ}$ ao $2^{\circ}$ ano; outro do $3^{\circ}$ ao $5^{\circ}$ ano; e o último, que aderiu ao PNLD 2020, do $6^{\circ}$ ao $9^{\circ}$ ano $^{7}$ (DARIDO et al., 2017a, 2017b, 2018).

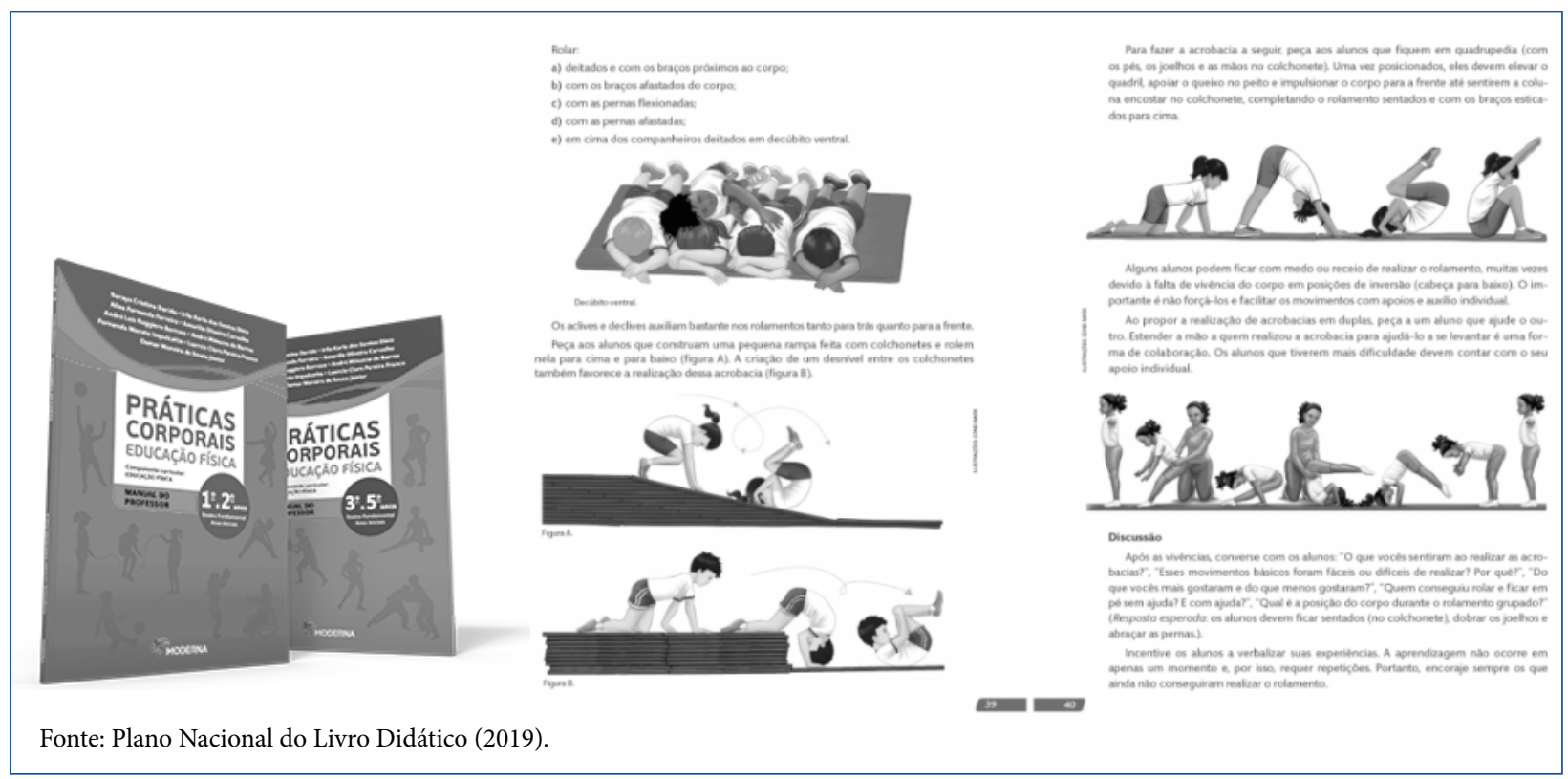

Figura 1. Manual do Professor de Educação Física.

Os três volumes desse livro foram publicados pela Editora Moderna, especializada em livros didáticos e integrante do Grupo Santillana. Essa editora é mais um exemplo da "norma corporativa" a que Goodson (2014) se refere: teve como fundador o professor Ricardo Feltre e atualmente é controlada por um conglomerado de atuação internacional. Por sua vez, o Grupo Santillana tem se destacado no mercado brasileiro pela disputa por diferentes "insumos curriculares", como livros didáticos, tablets, softwares entre outras tecnologias (ADRIÃO, 2017). No site do Grupo Santillana ${ }^{8}$ 
constatamos seu alinhamento às redes globais descritas por Ball (2014), assim como sua vertente "filantrópica".

Com forte presença nas Américas e na Europa, o Grupo Santillana tem o compromisso global de entender a identidade, a missão e o momento de cada instituição educacional, a fim de fomentar um mundo integrado de vivências e descobertas em constante movimento [...]. Na área social, atua por meio da Fundação Santillana, instituição voltada ao fomento da educação e difusão da cultura no país, que realiza diversas ações em parceria com organismos nacionais e internacionais, como Unesco, OCDE, OEI, Movimento Todos Pela Educação, entre outros (GRUPO SANTILLANA, 2019).

A proposta do livro em destaque é servir, baseado nos pressupostos da BNCC, como um manual para o professor de Educação Física, anunciando que fará a diferença para a Educação Física pelos seguintes motivos:

- Valorização do professor de Ed. Física como agente de transformação social;

- Teoria aliada à prática de modo objetivo e consistente;

- Unidades temáticas com sugestões práticas: brincadeiras/jogos, esportes, dança, ginástica geral e lutas;

- Atividades de fácil aplicação para as diferentes realidades escolares

- Adaptação de atividades para alunos com deficiência física, visual ou auditiva;

- Fotos e ilustrações técnicas das práticas que exigem movimentos corporais específicos;

- Propostas de avaliação (PLANO..., 2019).

Portanto, o manual está voltado para aplicação de conteúdos práticos. Nesse sentido, a própria adoção do termo "manual" para designar os livros do professor publicados no período pós-BNCC reforça o instrumental que se apodera da prática pedagógica do professor. A utilização em comum do termo "manual" em todos os livros da Tabela 4 é explicada pela exigência dos editais divulgados pelo PNLD (BRASIL, 2018), que preconizam justamente oferecer subsídios práticos para a ação docente na escola. Dessa forma, para aprovação no PLND os manuais precisaram contemplar os seguintes critérios específicos:

1. A relação proposta pelas coleções entre os objetos de conhecimento e as habilidades propostas na Base Nacional Comum Curricular para o componente Educação Física nos anos iniciais do Ensino Fundamental;

2. As competências gerais da Base Nacional Comum Curricular;

3. As competências específicas de linguagens para o Ensino Fundamental (BRASIL, 2018, p. 13).

Dessa maneira, cada capítulo dos manuais está alinhado aos pressupostos técnicos da BNCC, aos seus conteúdos (objetos de conhecimento) e seus objetivos (competências e habilidades) (Figura 2). A base reforça, segundo Neira (2018) e Novaes, Triani e Telles (2020), o discurso da eficiência na educação e remete ao movimento eficientista de currículo nos Estados Unidos na década de 1950, já descrito por Silva (2010) e Lopes e Macedo (2011). Nesse contexto, a educação é concebida como uma série de elementos técnicos que, encadeados, garantem a aprendizagem. 


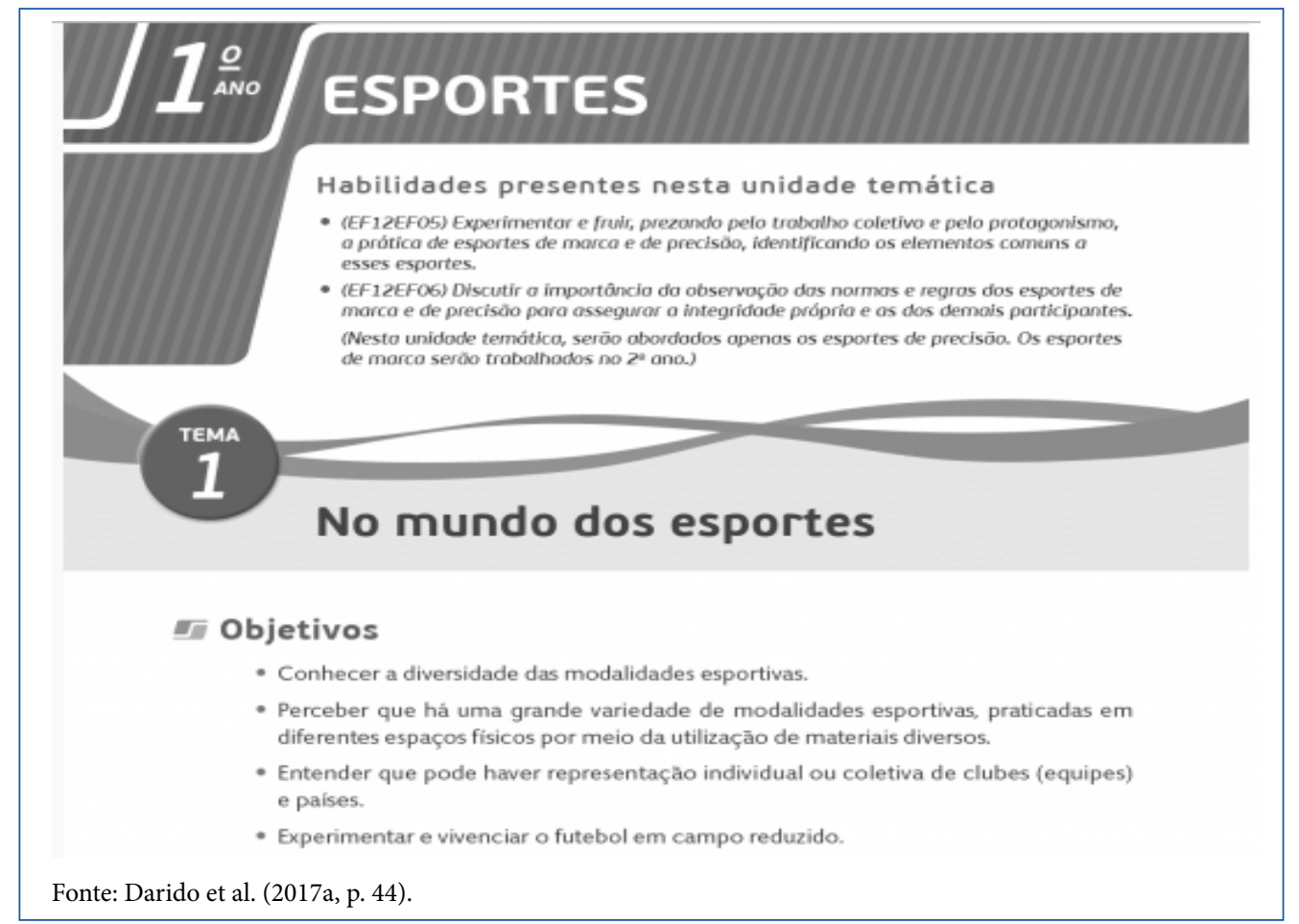

Figura 2. Indicação das habilidades no Manual para o Professor de Educação Física.

Reforçamos aqui a possível influência dos "manuais do professor" para a EFE. Apesar de Goodson e Petrucci-Rosa (2018) afirmarem que a Educação Física, assim como Português, História, Geografia, entre outras disciplinas, são matérias estáveis nos currículos escolares brasileiros desde o início do século passado, não podemos deixar de destacar que, conforme apontamos na seção anterior, apenas recentemente a Educação Física foi reconhecida como componente curricular, em contraposição ao status anterior de atividade. Para Goodson e Petrucci-Rosa (2018), as disciplinas mais recentes nos currículos escolares se mostram menos refratárias a mudanças. Nesse sentido, consideramos que a emergência de materiais pedagógicos como os manuais dos professores possui menor chance de refração, especialmente pelos professores que atuam na escola. Isso implicaria maior influência da linguagem técnica da BNCC, dos manuais do professor, dos cursos de capacitação, enfim, de tudo que atravessa o espaço-tempo escolar e desemboca nessa disciplina escolar. Tal inflexão no campo da EFE sugere uma espécie de esvaziamento do debate acadêmico sobre o papel dessa disciplina na escola em favor de um tipo de instrumentalismo didático-pedagógico.

A crítica aqui não se direciona especificamente aos livros citados, aos envolvidos no Impulsiona ou aos elaboradores da BNCC. Interessa-nos, neste texto, apontar como se revelam novos dispositivos que fazem parte daquilo que Goodson (2014) aponta como norma corporativa e que geram mudanças nas disciplinas escolares. Chama a atenção uma nova configuração no campo da EFE, que coaduna com o discurso mercadológico na educação e, ao mesmo tempo, retoma a perspectiva de "atividade" nos currículos escolares.

As forças externas atuais se afirmam como dispositivos práticos e discursivos nos quais escola e currículo são geridos a partir de pressupostos empresariais. Qual seria o projeto identitário de currículo que emergiria na norma corporativa? Para Carvalho, Silva e Delboni (2017), trata-se da formação do que Foucault chamou homo oeconomicus neoliberal, no qual o sujeito não é mais do que "um parceiro de troca, é um empresário de si mesmo, ele próprio é seu capital, a fonte de renda" (1995, p. 311). Assim, a concepção de educação é pensada a partir de uma lógica funcional que deve preparar pessoas "economicamente ativas, 
produtivas e voltadas para a empregabilidade e as competências e habilidades requeridas" (CARVALHO; SILVA; DELBONI, 2017, p. 499).

Nesse sentido, como afirmam Lopes e Macedo, os discursos hibridizam "sentidos pedagógicos, científicos, sociais, psicológicos e vão constituindo um discurso disciplinar que contribui para a ideia de que existe uma cultura comum que deve ser ensinada a todos" (2011, p. 121). Tais discursos penetram todas as esferas da vida, tratando as relações humanas - no nosso caso, educativas - como relações da lógica neoliberal. Para Foucault,

[...] cada sociedade tem seu regime de verdade, sua "política geral" de verdade: isto é, os tipos de discursos que ela acolhe e faz funcionar como verdadeiros; os mecanismos e instâncias que permitem distinguir os enunciados verdadeiros dos falsos; a maneira como se sanciona uns e outros; as técnicas e os procedimentos que são valorizados para a obtenção da verdade; o estatuto daqueles que têm o encargo de dizer o que funciona como verdadeiro (1986a, p. 12).

Ampliamos, assim, o conceito de norma corporativa adotado por Goodson (2014) para uma perspectiva discursiva que pretende fixar um sentido de verdade nos sujeitos, nos saberes e nos próprios discursos (FOUCAULT, 1986b). A norma corporativa não se restringe ao campo do currículo, mas atravessa os discursos presentes na sociedade. Assim, o discurso neoliberal não se encontra em campos específicos, como no educativo, mas está em todo lugar. Como afirma Ball,

[...] o neoliberalismo está "aqui dentro" bem como "lá fora". Ou seja, o neoliberalismo é econômico (um rearranjo das relações entre o capital e o Estado), cultural (novos valores, sensibilidades e relacionamentos) e político (uma forma de governar, novas subjetividades). [...] em um sentido paradoxal, o neoliberalismo trabalha a favor e contra o Estado de maneiras mutuamente constitutivas. Ele destrói algumas possibilidades para formas mais antigas de governar e cria novas possibilidades para novas formas de governar (BALL, 2014, p. 229).

Nos valemos, portanto, de Ball (2014), para compreender a passagem do conceito de norma corporativa, adotado por Goodson (2014), para uma perspectiva discursiva. Ao tratar das redes políticas, Ball (2014) reconhece as condições materiais e sociais do neoliberalismo e que visam ao lucro. Também se apodera do conceito de homo oeconomicus de Foucault, particularmente "por meio da produção de seres empreendedores 'dispostos', 'autogovernamentáveis', que está reconfigurando as relações entre governantes e governados, poder e conhecimento, soberania e territorialidade" (BALL, 2014, p. 26). De tal modo, Ball (2014) articula e dialoga com referenciais teóricos distintos para entender, por um lado, as condições materiais, por outro, as condições discursivas que conferem certo sentido de verdade. ${ }^{9}$

Desse modo, Goodson (2014) aponta as forças externas à comunidade escolar, ligadas ao mercado, como novas geradoras da mudança nas disciplinas escolares. De fato, podemos perceber que novos atores sociais e instituições privadas e públicas são responsáveis por novas configurações nas disciplinas escolares. No entanto, pensando a partir de uma perspectiva discursiva, destacamos que o discurso neoliberal se encontra capilarizado em toda a sociedade, inclusive nas forças internas de mudança curricular. Isso não invalida a concepção de mudança apresentada por Goodson (2014); pelo contrário, amplia sua aplicação.

Voltando ao currículo e para seus insumos, observamos que a elaboração da BNCC, as instituições "filantrocapitalistas" e as editoras dos livros didáticos contam também com a participação dos agentes internos, ou seja, de professores e pesquisadores, esses últimos cooptados como selo de legitimação do processo. Pensar em termos de um regime de verdade que se expressa discursivamente nos ajuda a compreender que as forças 
externas e a norma corporativa não existem fora dos sujeitos; muito pelo contrário, se apoderam das formas de pensar e validam as mudanças curriculares diante da sociedade.

No entanto, como bem aponta Foucault (1986b), o discurso estabelecido como verdadeiro sempre encontra formas de resistência. Além disso, como nos lembra Goodson (2013), os grupos sociais são formados por conflito. Dessa forma, a comunidade acadêmica não pode ser entendida como entidade homogênea e hegemônica, pois nela circulam diferentes discursos. Na edição especial sobre a Educação Física na BNCC da revista Motrivivência, ${ }^{10}$ por exemplo, encontramos diferentes posicionamentos sobre a necessidade de uma BNCC. É preciso ressaltar que, por vezes, os mesmos pesquisadores que se posicionam favoráveis à BNCC são também autores de livros didáticos fomentados pelo PNLD, como é o caso de Boscatto, Impolcetto e Darido (2016). Novamente, o importante aqui não é realizar uma crítica aos indivíduos que participaram desse processo como profissionais, mas apontar como as práticas discursivas perpassam também o campo do que Goodson (2014) chama de agentes internos, assim como toda a estrutura social.

Diante do exposto ao longo desta seção, argumentamos que a Educação Física está inserida em um processo de transição no qual o discurso neoliberal se apodera vertiginosamente da concepção dessa disciplina escolar; ou seja, do próprio raciocínio estruturante do currículo da Educação Física. Enfim, as forças externas no momento exercem mais pressão sobre as políticas curriculares que as forças internas. Isso não se dá sem a cooptação de parte dos agentes internos da academia que legitimam o processo em curso.

\section{Considerações Finais}

Minha opinião é que nem tudo é ruim, mas tudo é perigoso, o que não significa exatamente o mesmo que ruim. Se tudo é perigoso, então temos sempre algo a fazer (FOUCAULT, 1995, p. 256).

Ao longo deste artigo, procuramos destacar a emergência de novos atores e instituições no processo de constituição da EFE, entendida como uma disciplina escolarizada. Enquanto, num primeiro momento, as forças internas à comunidade escolar foram as principais responsáveis pelas mudanças curriculares, recentemente observamos novos dispositivos de poder alinhados à lógica neoliberal (forças externas), que agem diretamente sobre as políticas de currículo e práticas/produtos que o permeiam.

Limitamo-nos, portanto, a apresentar tais dispositivos de forma a indicar que o novo padrão de mudança proposto por Goodson (2014) está em pleno andamento na EFE brasileira. Conforme questiona Goodson (2014), resta saber qual será, daqui para a frente, a força de sustentação desses agentes externos. Para esse autor, o que inexiste nesse novo modelo é o engajamento pessoal e coletivo que deve existir no seio de qualquer reforma curricular, considerando que as mudanças em tempos de norma corporativa são impessoais e geridas a partir de uma concepção técnica e instrumental de ensino.

Como aponta Foucault (1995), não nos cabe dizer se tais mudanças são essencialmente ruins. É possível que a BNCC, os grupos "filantrocapitalistas", os livros didáticos, entre outros insumos curriculares, possam suprir algumas das lacunas apresentadas por críticos às teorizações curriculares dos movimentos renovadores da Educação Física. Entre elas está que tradições acadêmicas da EFE "não alcançaram uma consistência sistematizadora, sendo que [...] se configuraram mais claramente em perspectivas de análises, ou até mesmo, em ensaios propositivos" (CORREIA, 2012, p. 176). Por outro lado, não podemos ignorar que os estudos no campo da educação não indicam efeitos positivos das mudanças curriculares em tempos de norma corporativa sobre a qualidade do ensino. 
Alinhamo-nos à posição de Taubman (2009), ao se revelar pessimista diante das reformas neoliberais de currículo. Isso porque as forças estão muito enraizadas nos discursos vigentes - que certamente não são monolíticos -, mas parecem não ceder espaço para opiniões divergentes. Sua expectativa, e nossa também, é de que a problematização aqui apresentada seja profícua para problematizarmos esse debate na disciplina específica e no campo da educação diante das novas alternativas de mudança. No momento, somos passageiros inquietos da atual onda de mudanças na educação.

\section{Contribuição dos Autores}

Problematização e conceitualização: Novaes R; Telles S; Metodologia: Novaes R; Triani F; Soares A; Telles S; Análise: Novaes R; Triani F; Soares A; Telles S; Redação: Novaes R; Triani F; Soares A; Telles S.

\section{Notas}

1. Como a palavra inglesa rule pode ser traduzida tanto por "norma" quanto por "regra", optamos pela primeira por se adequar melhor ao conceito de normatividade no campo do currículo, utilizado por Lopes (2015).

2. Propaganda do Ministério da Educação sobre a Base Nacional Comum Curricular veiculada nos meios de comunicação, com início em 2018.

3. Disponível em: https://novaescola.org.br/conteudo/5081/vagas-e-oportunidades-com-recursos-gratuitos-institutopeninsula-quer-promover-a-educacao-fisica. Acesso em: jun. 2019.

4. Disponível em: https://impulsiona.org.br/saiba-tudo-sobre-a-bncc-da-educacao-fisica/. Acesso em: jul. 2020.

5. Disponível em: https://g1.globo.com/economia/noticia/kroton-fecha-compra-da-somos-educacao-por-r-46bilhoes.ghtml. Acesso em: jun. 2019.

6. Disponível em: https://www.fnde.gov.br/index.php/programas/programas-do-livro/pnld/dados-estatisticos. Acesso em: jun. 2019.

7. Coleção aprovada no edital do PNLD 2019. Código da obra 0184P19161.

8. Disponível em: https://www.gruposantillana.com.br/web/gruposantillana/santillana. Acesso em: jun. 2019.

9. Nesse sentido, a noção de discurso em Foucault, inserido numa perspectiva pós-estruturalista, não encerra o estruturalismo, no qual o trabalho de Goodson pode ser classificado. O pós-estruturalismo consiste numa outra perspectiva teórica, que vai para além das divisões estruturais típicas (WILLIAMS, 2005).

10. Volume 28, número 48, de 2016.

\section{Referências}

ADRIÃO, T. A privatização dos processos pedagógicos: grupos editoriais e os negócios na educação básica. In: MARINGONI, G. et al. (org.) O negócio da educação: aventuras na terra do capitalismo sem risco. São Paulo: Olho d’Água, 2017. 
ADRIÃO, T; DOMICIANO, C. A educação pública e as corporações: avanços e contradições em uma década de ampliação de investimento no Brasil. Revista de Financiamento da Educação, Porto Alegre, v. 8, n. 3, p. 1-18, 2018. https://doi.org/10.17648/fineduca-2236-5907-v8-79084

ADRIÃO, T. et al. Grupos empresariais na educação básica pública brasileira: limites à efetivação do direito à educação. Educação \& Sociedade, Campinas, v. 37, n. 134, p. 113-131, mar. 2016. https://doi.org/10.1590/ ES0101-73302016157605

AGUIAR, M.; DOURADO, L. F. (orgs.). A BNCC na contramão do PNE 2014-2024: avaliação e perspectivas. Recife: ANPAE, 2018.

BALL, S. Educação global S.A.: novas redes políticas e o imaginário neoliberal. Ponta Grosa: Editora UEPG, 2014.

BASE Nacional Comum Curricular. [S. 1., s. n.], 2018. 1 vídeo (0,32 s). Publicado pelo canal Ministério da Educação. Disponível em: https://www.youtube.com/watch?v=Fbz-cpct1W4. Acesso em: 20 jan. 2020.

BOOG, A. C.; URIZZI, E. Práticas corporais e a Educação Física escolar: 1 e $2^{\circ}$ anos. São Paulo: Boreal Edições, 2018a.

BOOG, A. C.; URIZZI, E. Práticas corporais e a Educação Física escolar: 3 a $5^{\circ}$ anos. São Paulo: Boreal Edições, 2018b.

BOSCATTO, J.; IMPOLCETTO, F.; DARIDO, S. A Base Nacional Comum Curricular: uma proposição necessária para a Educação Física? Revista Motrivivência, Florianópolis, v. 28, n. 48, p. 96-112, 2016. https:// doi.org/10.5007/2175-8042.2016v28n48p96

BOUDON, R. Education, opportunity, and social inequality: changing prospects in Western society. Nova York: Wiley, 1974.

BRACHT, V. Educação Física no $1^{\circ}$ Grau: conhecimento e especificidade. Revista Paulista de Educação Física, São Paulo, suplemento n. 2, p. 23-28, 1996. https://doi.org/10.11606/issn.2594-5904.rpef.1996.139640

BRACHT, V. A constituição das teorias pedagógicas da educação física. Caderno Cedes, Campinas, v. 19, n. 48, p. 69-88, 1999. https://doi.org/10.1590/S0101-32621999000100005

BRACHT, V. A educação física escolar no Brasil: o que ela vem sendo e o que pode ser. Ijuí: Editora Unijuí, 2019.

BRANDOLIN, F.; KOSLINSKI, M. C.; SOARES, A. J. A percepção dos alunos sobre a educação física no ensino médio. Revista de Educação Fisica/UEM, Maringá, v. 26, n. 4, p. 601-610, 2015. https://doi.org/10.4025/ reveducfis.v26i4.29836

BRASIL. Ministério da Educação e Cultura. Decreto-Lei n. 69450, de $1^{\circ}$ de novembro de 1971. Brasília, DF: Conselho Federal de Educação, 1971.

BRASIL. Lei n. 9.394, de 20 de dezembro de 1996. Estabelece as Diretrizes e Bases da Educação Nacional. Legislação. Brasília, DF: Presidência da República, dez. 1996.

BRASIL. Ministério da Educação e Cultura. Secretaria de Educação Média e Tecnológica, Parâmetros Curriculares Nacionais. Brasília, DF: MEC, 1998. 
BRASIL. Decreto n. 9.099, de 18 de julho de 2017. Brasília, DF: Presidência da República, 2017. Disponível em: http://www.planalto.gov.br/ccivil_03/_ato2015-2018/2017/decreto/D9099.htm. Acesso em: 20 jan. 2020. BRASIL. Ministério da Educação. Secretária de Educação Básica. Fundo Nacional de Desenvolvimento da Educação. PNLD 2019: Educação Física - guia de livros didáticos. Brasília, DF: Ministério da Educação/ Secretária de Educação Básica, 2018.

CARVALHO, J.; SILVA, S.; DELBONI, T. A Base Nacional Comum Curricular e a produção biopolítica da educação como formação de "capital humano". e-Curriculum, São Paulo, v. 15, n. 2, p. 481-503, 2017. https:// doi.org/10.23925/1809-3876.2017v15i2p481-503

CORREIA, W. Educação Física Escolar: entre inquietudes e impertinências. Revista Brasileira de Educação Física e Esporte, São Paulo, v. 26, n. 1, p. 171-78, jan./mar. 2012. https://doi.org/10.1590/ S1807-55092012000100016

CORREIA, W. Educação Física Escolar: desafiando a sua presumível imutabilidade. Revista Brasileira de Educação Física e Esporte, São Paulo, v. 28, n. 4, p. 691-700, out./dez. de 2014. https://doi. org/10.1590/1807-55092014000400691

DARIDO, S. et al. Práticas corporais: Educação Física: $1^{\circ}$ a $2^{\circ}$ anos: Manual do Professor. São Paulo: Moderna, 2017a.

DARIDO, S. et al. Práticas corporais: Educação Física: $3^{\circ}$ a $5^{\circ}$ anos: Manual do Professor. São Paulo: Moderna, 2017b.

DARIDO, S. et al. Práticas corporais: Educação Física: $6^{\circ}$ a $9^{\circ}$ anos: Manual do Professor. São Paulo: Moderna, 2018.

FOUCAULT, M. Microfísica do poder. Rio de Janeiro: Graal, 1986a.

FOUCAULT, M. A arqueologia do saber. Rio de Janeiro: Forense, 1986b.

FOUCAULT, M. O sujeito e o poder. In: RABINOW, P.; RABINOW, H. Michel Foucault: uma trajetória filosófica (para além do estruturalismo e da hermenêutica). Rio de Janeiro: Forense Universitária, 1995.

GOODSON, I. Tornando-se uma matéria acadêmica: padrões de explicação e evolução. Teoria \& Educação, Porto Alegre, n. 2, 1990.

GOODSON, I. Social Histories of Educational Change. Journal of Educational Change, v. 2, n. 1, p. 45-63, 2001. https://doi.org/10.1023/A:1011508128957

GOODSON, I. Currículo: Teoria e História. 14. ed. Petrópolis: Vozes, 2013.

GOODSON, I. Context, curriculum and professional knowledge, History of Education. Journal of the History of Education Society, Tavistock, v. 43, n. 6, p. 768-776, 2014. https://doi.org/10.1080/0046760X.2014.943813

GOODSON, I.; PETRUCCI-ROSA, M. I. The journey of school knowledge in High School and the concept of refraction. Revista Pró-posições, Campinas, v. 29, n. 1, 2018. https://doi.org/10.1590/1980-6248-2016-0052

GRUPO SANTILLANA. Quem somos. Grupo Santillana, 2019. Disponível em: https://www.gruposantillana. com.br/web/gruposantillana/santillana. Acesso em: jun. 2019.

JAEHN, L.; FERREIRA, M. S. Perspectivas para uma História do Currículo: as contribuições de Ivor Goodson e Thomas Popkewitz. Currículo sem Fronteiras, Braga, v. 12, n. 3, p. 256-272, set./dez. 2012. 
LEOPOLDINO, L. et al. Encontros Educação Física: 1º e 2º anos. São Paulo: FTD Educação, 2018a. LEOPOLDINO, L. et al. Encontros Educação Física: 3º $4^{\circ}$ e $5^{\circ}$ anos. São Paulo: FTD Educação, 2018b. LOPES, A. C. Normatividade e intervenção política: em defesa de um investimento radical. In: LOPES, A. C.; MENDONÇA, D. (orgs.). A teoria do discurso de Ernesto Laclau: ensaios críticos e entrevistas. São Paulo: Annablume, 2015.

LOPES, A. C.; MACEDO, E. Teorias de currículo. São Paulo: Cortez, 2011.

LOVELESS, T. The 2016 Brown Center report on American education. Washington: Brookings Institution, 2016.

MACEDO, E. Base Nacional Curricular Comum: Novaes Formas de Sociabilidade Produzindo Sentidos para Educação. e-Curriculum, São Paulo, v. 12, n. 3, p. 1530-1555, 2014.

MACEDO, E. O que é a base? E o currículo o que é? In: AGUIAR, M.; DOURADO, L. F. (orgs.). A BNCC na contramão do PNE 2014-2024: avaliação e perspectivas. Recife: ANPAE, 2018.

MACEDO, E. A educação e a urgência de "desbarbarizar" o mundo. e-Curriculum, São Paulo, v. 17, n. 3, p. 1101-1122, jul./set. 2019. https://doi.org/10.23925/1809-3876.2019v17i3p1101-1122

MARINGONI, G. et al. (orgs.) O negócio da educação: aventuras na terra do capitalismo sem risco. São Paulo: Olho d’Água, 2017.

MCCARTY, T. The impact of high-stakes accountability policies on Native American learners: Evidence from research. Teaching Education, Abingdon, v. 20, n. 1, p. 7-29, 2009. https://doi. org/10.1080/10476210802681600

MOREIRA, A. F. A qualidade e o currículo da educação básica brasileira. In: PARAÍSO, M. Antônio Flávio Barbosa Moreira: pesquisador em currículo. Belo Horizonte: Autêntica, 2010.

NEIRA, M. G. Incoerências e inconsistências da BNCC de Educação Física. Revista Brasileira de Ciências do Esporte, São Paulo, v. 40, n. 3, p. 215-223, 2018. https://doi.org/10.1016/j.rbce.2018.04.001

NOVAES, R. A Educação Física no Exame Nacional do Ensino Médio. 2015. 104 f. Dissertação (Mestrado em Ciências do Exercício e do Esporte) - Instituto de Educação Física e Desportos, Universidade do Estado do Rio de Janeiro, Rio de Janeiro, 2015.

NOVAES, R.; TRIANI, F.; TELLES, S. A Educação Física na Base Nacional Comum Curricular: desconstruindo o discurso neoliberal. Revista Humanidades \& Inovação, Palmas, v. 7, n. 10, 2020.

NUNES, M.; RÚBIO, K. O(s) currículo(s) da Educação Física e a constituição da identidade de seus sujeitos. Currículo sem Fronteiras, Braga, v. 8, n. 2, p. 55-77, jul./dez. 2008.

OLIVEIRA, A. C.; PETRUCCI-ROSA, M. I. Recontextualizações e hibridismos em processos de elaboração e avaliação de livros didáticos de Química. Química Nova Escola, São Paulo, v. 38, n. 3, p. 273-283, 2016. https://doi.org/10.21577/0104-8899.20160038

PLANO NACIONAL DO LIVRO DIDÁTICO 2019. Editora Moderna. 2019. Disponível em: https:// pnldf1.moderna.com.br/educacaofisica/praticascorporais. Acesso em: fev. 2021. 
POPKEWITZ, T.; LINDBLAD, S. A fundamentação estatística, o governo da educação e a inclusão e exclusão sociais. Educação \& Sociedade, Campinas, v. 37, n. 136, p. 727-754, 2016. https://doi.org/10.1590/ es0101-73302016165508

RAVITCH, D. Vida e morte do grande sistema escolar americano: como os testes padronizados e o modelo de mercado ameaçam a educação. Porto Alegre: Sulina, 2011.

REID, A. Is this a revolution?: A critical analysis of the Rudd government's national education agenda. Curriculum Perspectives, Singapore, v. 29, n. 3, p. 1-13, 2009.

SILVA, T. T. Documentos de identidade: uma introdução às teorias do currículo. 3. ed. Belo Horizonte: Autêntica, 2010.

STALLIVIERI, R. Manual do professor para a Educação Física: $1^{\circ}$ ao $2^{\circ}$ ano. Curitiba: Terra Sul, 2017.

STALLIVIERI, R. Manual do professor para a Educação Física: $3^{\circ}$ ao $5^{\circ}$ ano. Curitiba: Terra Sul, 2018.

TAUBMAN, P. Teaching by numbers: deconstructing the discourse of standards and accountability in education. Nova York: Routledge, 2009.

WILLIAMS, J. Pós-estruturalismo. 2. ed. Petrópolis: Vozes, 2005.

\section{Sobre os Autores}

Renato Cavalcanti Novaes é professor na Marinha do Brasil. Doutorando e mestre em Ciências do Exercício e do Esporte pela Universidade do Estado do Rio de Janeiro (UERJ). Membro do Grupo de Pesquisa Escola, Esporte e Cultura (GPEEsC).

Felipe da Silva Triani é professor na Universidade Estácio de Sá. Doutorando em Ciências do Exercício e do Esporte pela Universidade do Estado do Rio de Janeiro (UERJ) e mestre em Humanidades, Culturas e Artes pela Universidade do Grande Rio (Unigranrio). Membro do Grupo de Pesquisa Escola, Esporte e Cultura (GPEEsC).

Antonio Jorge GonçAlves Soares é professor titular da Faculdade de Educação da Universidade Federal do Rio de Janeiro (UFRJ). Docente permanente do Programa de Pós-graduação em Educação, linha de pesquisa Políticas Públicas e Instituições Educacionais. Líder do Laboratório de Pesquisas em Educação do Corpo (LABEC). Bolsista Produtividade PQ-CNPq. Doutor em Educação Física e Cultura pela Universidade Gama Filho.

Silvio de Cassio Costa Telles é professor adjunto da Universidade Federal do Rio de Janeiro (UFRJ) e da Universidade do Estado do Rio de Janeiro (UERJ), onde atua, respectivamente, no Programa de Pós-graduação em Educação Física e no Programa de Pós-graduação em Ciências do Exercício e do Esporte. Líder do Grupo de Pesquisa Escola, Esporte e Cultura (GPEEsC). Doutor em Educação Física e Cultura pela Universidade Gama Filho.

Recebido: 08 fev. 2020

Aceito: 17 nov. 2020 